\title{
DETERMINAÇÃO DO FATOR DE CONVERSÃO EM COLÔNIAS DE Atta sexdens rubropilosa (Hymenoptera: Formicidae) E SUA RELAÇÃO COM A QUALIDADE DO MATERIAL VEGETAL CORTADO ${ }^{1}$
}

\author{
Leandro Sousa-Souto², Marcelo Braga Bueno Guerra ${ }^{3}$, José Henrique Schoereder ${ }^{4}$, Carlos Ernesto \\ Gonçalves Reynaud Schaefer ${ }^{5}$ e Washington Luis da Silva ${ }^{3}$
}

\begin{abstract}
RESUMO - As formigas cortadeiras (Atta e Acromyrmex) são consideradas importantes pragas na agricultura e silvicultura, mas pouco se sabe sobre os reais danos dessas espécies. Uma forma bastante difundida de avaliação do dano é por meio do cálculo da taxa de conversão, dividindo-se o peso do material cortado pelo peso de lixo produzido pelas colônias. Foi levantada a hipótese de que a qualidade do substrato cortado pode influenciar no forrageamento das operárias, alterando a taxa de conversão e dificultando as estimativas de dano. A taxa de conversão de oito colônias de Atta sexdens rubropilosa Forel (Hymenoptera: Formicidae) foi calculada com duas espécies vegetais com diferentes concentrações de lignina e celulose, para testar essa hipótese. Colônias mantidas com folhas de baixa qualidade (razão lignina/celulose elevada) tiveram maior forrageamento e produziram mais lixo. Entretanto, a taxa de conversão das colônias foi semelhante com essas duas plantas (média $=1,54)$. Esse valor está dentro da variação encontrada para outras espécies no campo $(1,5-1,8)$, indicando um fator semelhante de conversão entre os gêneros Atta e Acromyrmex. O consumo médio de material vegetal, em termos de pesos seco e fresco, de uma colônia de A. sexdens rubropilosa com 4.500 operárias, foi estimado em 520 e $1.100 \mathrm{~g} / \mathrm{ano}$, respectivamente.
\end{abstract}

Palavras-chave: Herbivoria, fator de conversão, formigas cortadeiras and fungo simbionte.

\section{DETERMINATION OF THE CONVERSION FACTOR IN COLONIES OF Atta sexdens rubropilosa (Hymenoptera: Formicidae) AND ITS RELATIONSHIP WITH THE QUALITY OF HARVESTED LEAF SUBSTRATE}

\begin{abstract}
Leaf-cutting ants (Atta and Acromyrmex) are important pests in agriculture and forestry, although few data exist on the actual damage caused by these species. A model used to evaluate damage by leafcutting ants are estimates of the conversion factor, which is the ratio between the weight of material cut by the ants and the refuse produced by the colonies. The hypothesis that substrate quality influences foraging by workers, modifying the conversion factor and impairing damage estimates was put forward. To test this hypothesis, the conversion factor was calculated for eight colonies of Atta sexdens rubropilosa Forel (Hymenoptera: Formicidae), using two plant species, with different lignin and cellulose concentrations. Colonies maintained with low quality leaves (high lignin/cellulose ratio) presented higher foraging activity and produced more refuse than colonies maintained with high quality leaves. However, the conversion factors obtained for the two groups of leaf-cutting ant colonies (average $=1.54$ ) was within the variation found for other species in the field (1.5 - 1.8), indicating a similar conversion factor in Atta and Acromyrmex. The average consumption in both dry and fresh weight of plant material of a colony of Atta sexdens rubropilosa with 4,500 workers was estimated as 520 and 1,100 g/year, respectively.
\end{abstract}

Keywords: Conversion factor, leaf-cutting ants, herbivory and symbiotic fungus.

\footnotetext{
${ }^{1}$ Recebido em 14.05.2006 e aceito para publicação em 21.10.2006.

${ }^{2}$ Programa de Pós-Graduação em Entomologia da UFV, 36570-000 Viçosa-MG. E-mail:<leandroufv@ gmail.com>.

${ }^{3}$ Bolsistas IC-FAPEMIG/CNPq, UFV, 36570-000 Viçosa-MG. E-mail:<marcelobbg@ gmail.com>, <washington@vicosa.ufv.br>.

${ }^{4}$ Departamento de Biologia Geral da UFV. E-mail:<jschoere@ufv.br $>$.

${ }^{5}$ Departamento de Solos da UFV. E-mail: <carlos.schaefer@ufv.br>.
} 


\section{INTRODUÇÃO}

As formigas-cortadeiras (Atta e Acromyrmex) são consideradas importantes pragas da agricultura e silvicultura na região neotropical (FOWLER et al., 1990), mas desempenham papel importante na ciclagem de nutrientes, modificando as propriedades físicas e químicas dos solos (COUTINHO, 1984; MOUTINHO et al., 2003). O acúmulo no subsolo de matéria orgânica do material vegetal cortado e incorporado ao fungo simbionte, bem como o material exaurido e carcaças de formigas mortas (lixo) modificam os solos, por aumentar a concentração de nutrientes liberados durante o processo de decomposição da matéria orgânica. Contudo, a determinação do dano por herbivoria e a quantidade de material vegetal acumulado no interior das colônias dessas espécies é alvo de controvérsias (AUTUORI, 1947; JONKMAN, 1977; FOWLER et al., 1990). O cálculo da taxa de conversão é uma forma de avaliação do dano da herbivoria, dividindo-se o peso do material cortado pelo do lixo produzido (AUTUORI, 1947). Utilizandose esse método, as taxas de conversão de Atta vollenweideri Forel e Acromyrmex landolti Forel (Hymenoptera: Formicidae) foram estimadas em 1,5 e 1,8, respectivamente (JONKMAN, 1977). Entretanto, a qualidade do material cortado pode influenciar a produção de lixo (WEBER, 1976). Nesse caso, se a qualidade do substrato afeta essa produção, é possível que ela também altere as taxas de conversão das diferentes espécies de formigas-cortadeiras.

Recentes estudos têm demonstrado que o fungo simbionte cultivado pelas formigas-cortadeiras não é eficiente em degradar celulose e lignina (ABRIL e BUCHER, 2002; 2004) e reforçando a hipótese de que, apenas, 11-27\% do material vegetal incorporado ao jardim de fungo seja metabolizado (ROBBINS, 1993). A digestibilidade de um substrato por organismos decompositores pode ser avaliada pela sua razão lignina/ celulose, sendo que, quanto maior essa razão, menor a digestibilidade do material vegetal por esses organismos (LEE e WOOD, 1971). Por isso, plantas com razão lignina/ celulose elevada podem dificultar ainda mais a ação digestiva do fungo simbionte, sendo consideradas de baixa qualidade e requerendo maior forrageamento. Para testar essa hipótese, formigueiros de A. sexdens rubropilosa Forel, mantidos em laboratório, foram abastecidos com folhas de duas plantas, uma espécie arbustiva e outra lenhosa, tendo suas taxas de conversão sido comparadas.

R. Árvore, Viçosa-MG, v.31, n.1, p.163-166, 2007

\section{MATERIAL E MÉTODOS}

Oito colônias de $A$. sexdens rubropilosa, mantidas em laboratório há cinco anos, foram utilizadas. Cada colônia consistiu de um pote plástico ( 5 litros) acoplado a um pote cerâmico ( 1 litro) e a uma arena plástica de forrageamento $\left(35 \mathrm{~cm}^{2}\right)$, por meio de mangueiras de silicone $(\varnothing=2,5 \mathrm{~cm})$ (SOUSA-SOUTO e SOUZA, 2006). Um recipiente de $100 \mathrm{ml}$ foi colocado no centro da arena de forrageamento com algumas formigas mortas da colônia para que as operárias fossem condicionadas a depositar todo o lixo produzido nesse recipiente. As colônias, com aproximadamente $1.000 \mathrm{~cm}^{3} \mathrm{de}$ fungo e 4.500 operárias, foram divididas em dois grupos de quatro e abastecidas com folhas de Acalypha wilkesiana Müll. Arg. (Euphorbiacea) ou Bauhinia variegata L. (Caesalpiniaceae), durante 90 dias. Os primeiros 60 dias serviram para o condicionamento das colônias às folhas e para que o lixo fosse oriundo de um mesmo material vegetal. A determinação do fator de conversão foi feita durante os últimos 30 dias.

Após o condicionamento, todo o lixo foi retirado. e as folhas começaram a ser pesadas e oferecidas todos os dias. Além disso, diariamente, algumas amostras de folhas foram coletadas, pesadas, secadas em estufa a $60{ }^{\circ} \mathrm{C}$, por $24 \mathrm{~h}$, e novamente pesadas, para se obter o peso de matéria seca das amostras. O material não consumido pelas saúvas foi também retirado, secado e pesado, para ser descontado do peso total oferecido. O lixo produzido foi retirado semanalmente e seu peso de matéria seca, calculado. Esse procedimento foi repetido por quatro semanas consecutivas. Dessa forma, foi determinada a proporção de lixo em relação ao peso de folhas consumidas. Ao final das quatro semanas, amostras de folhas oferecidas e do lixo de cada colônia foram submetidas à análise das concentrações de celulose e lignina, para se avaliar a qualidade das folhas oferecidas. As amostras de lixo foram submetidas a uma triagem para a remoção de carcaças de formigas mortas. Na determinação de celulose e lignina, empregou-se o método de fibra em detergente ácido (FDA), baseado no método de van Soest e Robertson (1980), com adaptações propostas por Anderson e Ingram (1996). A influência do tipo de material vegetal (variável resposta) sobre o consumo de folhas, produção semanal de lixo, razão lignina/celulose, e o fator de conversão foi comparada nos dois grupos utilizando-se ANOVA. 


\section{RESULTADOS E DISCUSSÃO}

O consumo de folhas $(\mathrm{F}=16,74 ; \mathrm{p}<0,001)$ e a produção de lixo $(\mathrm{F}=7,82 ; \mathrm{p}=0,03)$ das colônias mantidas com $B$. variegata foram maiores do que os valores encontrados com relação às colônias mantidas com A. wilkesiana (Quadro 1). Entretanto, o consumo e a produção de lixo não variaram ao longo do tempo $(F=1,6 ; p=0,21)$. A maior razão lignina/ celulose nas folhas oriundas de $B$. variegata $(\mathrm{F}=$ 38,$2 ; \mathrm{p}<0,001$ ) (Figura 1) indica sua menor qualidade e pode ter sido o principal motivo para um maior consumo de folhas dessa planta.

Os fatores de conversão não diferiram entre as colônias mantidas com as duas espécies de plantas $(\mathrm{F}=1,03 ; \mathrm{p}=0,36)$, indicando que, independentemente do material vegetal forrageado, a taxa de conversão é semelhante (Quadro 1). Isso indica que a qualidade do material vegetal não afeta a taxa de conversão de colônias de A. sexdens rubropilosa, apesar de alterar a quantidade de material forrageado e a produção de lixo, como demonstrado inicialmente por Weber (1976).

O consumo vegetal médio anual dos formigueiros, em peso de matéria seca, foi de aproximadamente 520 g/ano (Quadro 1). Considerando o valor médio de $67 \%$ de umidade nas folhas utilizadas neste estudo, o valor em peso de matéria fresca é de aproximadamente $1.100 \mathrm{~g} /$ ano. Esses valores são expressivos, pois o número de operárias $( \pm 4.500)$ das colônias foi muito pequeno, em comparação com daquelas adultas dessa espécie em seu "habitat" (> 15 milhões de indivíduos) (AUTUORI, 1947; COUTINHO, 1984). Além disso, a densidade de colônias de $A$. sexdens rubropilosa pode ser superior a 50/ha (ARAÚJO et al., 1997;
ZANETTI et al., 2003), em povoamentos de Eucalyptus spp. Nesses povoamentos, a razão lignina/celulose nas folhas é superior a 1,2 (COSTA et al., 2005), ou praticamente o dobro da encontrada em A. wilkesiana, indicando maior quantidade de biomassa vegetal incorporada aos ninhos e justificando o "status" de principais pragas herbívoras das formigascortadeiras nesses povoamentos. A utilização de variedades de Eucalyptus spp. com baixa razão lignina/ celulose pode ser uma alternativa para diminuição do dano provocado por essas formigas. Os fatores de conversão $(1,45-1,63)$ foram próximos aos de $A$. vollenweideri $(1,5)$ e Acromyrmex landolti $(1,8)$, em trabalhos de campo (JONKMAN, 1977), indicando que esses valores podem ser semelhantes entre diferentes espécies de formigas-cortadeiras e não variar com a qualidade do material transportado.

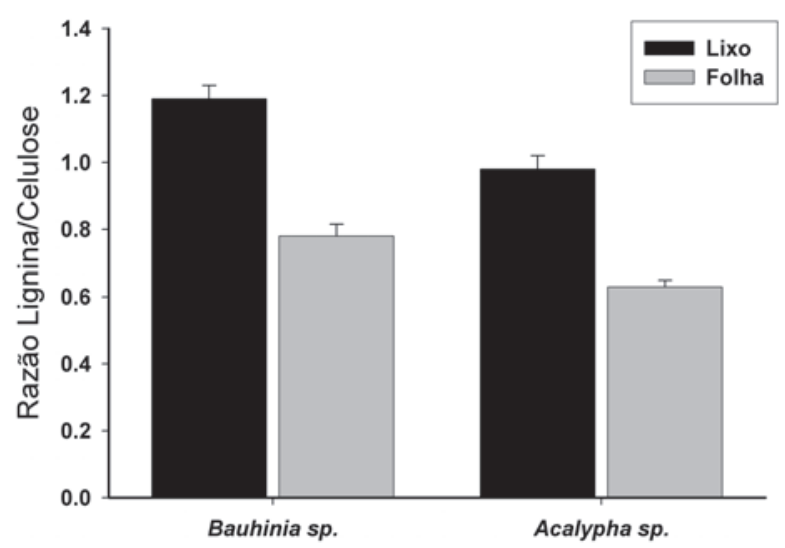

Figura 1 - Razão lignina/celulose no lixo de colônias de Atta sexdens rubropilosa Forel e nas folhas de duas espécies de plantas.

Figure 1 - Lignin/cellulose ratio in refuse of Atta sexdens rubropilos a Forel colonies and leaves of two plant species.

Quadro 1 - Valores (média \ EP) dos parâmetros avaliados em oito colônias de Atta sexdens rubropilosa Forel (Hymenoptera: Formicidae) submetidas a 30 dias de experimento, com dois diferentes substratos

Table 1 - Values (mean $\pm S E$ ) of evaluated parameters from eight Atta sexdens rubropilosa Forel (Hymenoptera: Formicidae) colonies, subjected of 30 days-period of experiment, with two different types of substrate

\begin{tabular}{|c|c|c|c|c|}
\hline $\begin{array}{l}\text { Tratamento } \\
\text { (substrato) }\end{array}$ & $\begin{array}{l}\text { Consumo }(\mathrm{g}) \\
(\text { peso seco) }\end{array}$ & $\begin{array}{c}\text { Lixo } \\
\text { produzido }(\mathrm{g})\end{array}$ & $\begin{array}{c}\text { Fator } \\
\text { de conversão }\end{array}$ & $\begin{array}{c}\text { Estimativa } \\
\text { consumo/ano }(\mathrm{g})\end{array}$ \\
\hline Acalypha wilkesiana & $32,48 \pm 7,18 \mathbf{a}$ & $21,85 \pm 3,3 \mathbf{a}$ & $1,45 \pm 0,11 \mathbf{a}$ & 390 \\
\hline Bauhinia variegata & $54,17 \pm 6,65 \mathbf{b}$ & $32,93 \pm 2,1 \mathbf{b}$ & $1,63 \pm 0,12 \mathbf{a}$ & 650 \\
\hline Média & 43,3 & 27,39 & 1,54 & 520 \\
\hline
\end{tabular}

Letras diferentes na mesma coluna indicam diferença significativa $(\mathrm{p}<0.05)$. 


\section{CONCLUSÕES}

Colônias de A. sexdens rubropilosa tendem a aumentar o consumo de material vegetal de baixa qualidade. A taxa de conversão dessa espécie é de aproximadamente 1,5 , independentemente da qualidade e quantidade de material forrageado. Esse valor é semelhante ao encontrado em outras espécies no campo, indicando um valor comum do fator de conversão para diferentes espécies de formigas-cortadeiras e de material vegetal transportado.

A hipótese de que a qualidade do substrato cortado pode influenciar a taxa de conversão não foi confirmada.

\section{AGRADECIMENTOS}

Ao CNPq e à FAPEMIG, pela concessão de bolsas de pesquisa; à The Nature Conservancy do Brasil, pelo auxílio financeiro; e à Maria do Carmo, pelo auxílio na manutenção das colônias.

\section{REFERÊNCIAS}

ABRIL, A. B.; BUCHER, E. H. Evidence that the fungus cultured by leaf-cutting ants does not metabolize cellulose. Ecology Letters, v.5, n.3, p.325-328, 2002.

ABRIL, A. B.; BUCHER, E. H. Nutritional sources of the fungus cultured by leaf-cutting ants. Applied Soil Ecology, v.26, n.3, p.243-247, 2004.

ANDERSON, J.D.; INGRAM, J.S.I. Tropical soil biology and fertility: A handbook of methods. 2. ed. Wallingford: CAB International, 1996. 171p.

ARAÚJO, M. S.; DELLA LUCIA, T. M. C.; MAYHÉ-NUNES, A. J. Levantamento de Attini (Hymenoptera: Formicidae) em povoamento de Eucalyptus na região de Paraopeba, Minas Gerais, Brasil. Revista Brasileira de Zoologia, v.14, n.2, p.323-328, 1997.

AUTUORI, M. Contribuição para o conhecimento da saúva (Atta spp.). VI - O sauveiro depois da primeira revoada (Atta sexdens rubropilosa Forel, 1908). Arquivos do Instituto de Biologia de São Paulo, v.18, n.1, p.39-70, 1947.

COSTA, G. S.; GAMA-RODRIGUES, A. C.; CUNHA, G. M. Decomposição e liberação de nutrientes da serapilheira foliar em povoamentos de Eucalyptus grandis no norte Fluminense. Revista Árvore, v.29, n.4, p.563-570, 2005.

R. Árvore, Viçosa-MG, v.31, n.1, p.163-166, 2007
COUTINHO, L. M. Aspectos ecológicos da saúva no cerrado. A saúva, as queimadas e sua possível relação na ciclagem de nutrientes minerais.

Boletim de Zoologia da Universidade de São Paulo, v.8, n.1, p.1-9, 1984.

FOWLER, H. G.; FORTI, L. C.; DI ROMAGNANO, L. F. T. Methods for the evaluation of leaf-cutting ant harvest. In: VANDER MEER, R.K.; JAFFE, K.; CEDENO, A. (Ed.), Applied Myrmecology: a world Perspective. Boulder: Westview Press, 1990. p.228-241.

JONKMAN, J. Determination of the vegetative material intake and refuse production ratio in two species of grass-cutting ants (Hym.: Attini).

Zeitschrift für Angewandte

Entomologie, v.84, n.1, p.25-34, 1977.

LEE, K. E.; WOOD, T. G. Termites and soils. London: Academic Press, 1971. 251p.

MOUTINHO, P.; NEPSTAD, D. C.; DAVIDSON, E. A. Influence of leaf-cutting ant nests on secondary forest growth and soil properties in Amazônia. Ecology, v.84, n.5, p.1265-1276, 2003.

ROBBINS, C. T. Wildlife feeding and nutrition. San Diego: Academic Press, 1993. 352p.

SOUSA-SOUTO, L.; SOUZA, D. J. Queen influence on workers behavior of the leaf-cutting ant Atta sexdens rubropilosa (forel, 1908). Brazilian Journal of Biology, v.66, n.4, 2006. (No prelo).

van SOEST, P. J.; ROBERTSON, J. B. Systems of analysis for evaluating fibrous feeds. In: PIGDEN, W. J.; BALCH, C. C.; GRAHAM, M. (Ed.) Standardization of analytical methodology for feeds. Ottawa: International Development Center and International Union of Nutritional Sciences, 1980. p.49-60.

WEBER, N. A. A ten-year laboratory colony of Atta cephalotes. Annals of Entomological Society of America, v.69, n.6, p.825-829, 1976.

ZANETTI, R. et al. Combate sistemático de formigas-cortadeiras com iscas granuladas, em eucaliptais com cultivo mínimo. Revista Árvore, v.27, n.3, p.387-392, 2003. 